\title{
Drape of Virtual Garments on Body Models: Impact of Mechanical Properties of the Fabrics
}

\author{
Evrim BUYUKASLAN ${ }^{* 1,2}$, Simona JEVSNIK ${ }^{1,3}$, Fatma KALAOGLU ${ }^{1}$ \\ ${ }^{1}$ Istanbul Technical University, Textile Technologies and Design Faculty, Turkey; \\ ${ }^{2}$ Istanbul Bilgi University, Fashion Design Department, Turkey; \\ ${ }^{3}$ University of Maribor, Faculty of Mechanical Engineering, \\ Institute of Textile Materials and Design, Slovenia
}

DOI: 10.15221/15.127 http://dx.doi.org/10.15221/15.127

\begin{abstract}
Virtual garments are expected to break a fresh ground for textile and apparel industry. When flawless virtual garments on virtual models are achieved, this triumph will hopefully put an end to costly prototype production and pave the way for shopping apparel online without any concerns. OptiTex is a CAD program that enables fashion designers to create their patterns and garments in a $3 D$ form. This program allows user to insert body measurements to obtain the virtual model. 3D scanned body images can be also exported to OptiTex to achieve garment simulations on realistic body shapes. Even though 3D scanned body models are identically with the real body shape, the simulated garments are not that realistic yet. One of the underlying reasons is that, allocation of the garment on the avatar depends on the drape of the garment which is strongly correlated to fabric's mechanical properties. Fabrics are non-linear, non-homogeneous, viscoelastic structures which makes them very complicated to identify. On the contrary to many other materials, fabrics are subjected to very low loads such as gravity, body motions, skin frictions and fabrics own internal frictions. In this research, bending rigidity, shear rigidity, extension, compression of three compositionally same woven fabrics (53\% polyester/ $43 \%$ wool, $4 \%$ elastane; plain weave) are measured by Fabric Assurance by Simple Testing (FAST) system. Drape ratio is another important fabric parameter which gives information about the formability of the fabric in real and virtual environment. "Cusick Drapemeter" is used to calculate drape ratio and number of drape nodes and amplitudes of the test fabrics. Finally real drape behaviors of these fabrics on a circular plate are compared with their virtual representations in OptiTex program in terms of drape ratios, node numbers and amplitudes. This study helps to understand how different fabrics drape on virtual avatars which can be provided from a 3D body scanner. At the end, the aim is to increase the interaction of garment and body model in virtual environment and obtain perfectly realistic representations of a virtual garment.
\end{abstract}

Keywords: $3 d$ body scanning, virtual garments, fabric drape, virtual body models

\section{Introduction}

Computers are widely used in textile and apparel industry during design, manufacturing and retailing stages. Simulating the flexible nature of fabrics is one of the complex tasks for computer technologist though it is essential for next generation Global Retailing System [1]. A satisfactory simulation of a fabric can bring a significant productivity and quality to apparel manufacturers. When fabrics are simulated realistically enough, this will enhance designers to pick the correct fabric according to their designs before seeing a garment sample. Not only design stage but manufacturing stage will also take less time as sample making and getting confirmation of the costumers are time consuming and costly because most of the manufacturers are situated overseas to costumers. Finally, even though e-retailing is widely used for apparel products [2], most of the people mention that they hesitate to purchase apparel products online because they cannot "feel" the fabric and predict how the garment will fit. Thus a realistic simulation of fabrics will satisfy designers, manufacturers, retailers and costumers of e-retailers.

However it is not that easy to simulate fabrics as fabric drape is a very complex phenomena. As explained by Kenkare and his colleagues this is due to limited understanding of 3D behavior of draped fabric. When mass-spring or interacting particle based models have been used to simulate fabric drape, accurate virtual representations may only be achieved by implementing the material mechanical property values [3]. Thus it is essential to understand well the correlation between fabric mechanical properties and drape to comprehend fabric simulation.

\footnotetext{
*evrim.buyukaslan@bilgi.edu.tr; +9-0535-7975016
} 
Fabric drape has been under investigation since 1930's [4]. Non-linear, non-homogenous and viscoelastic structure of fabrics make it difficult to predict their drape behavior. Moreover fabrics are subjected to very low loads, such as gravity, skin and yarn friction, when compared to many other material. Some systems have been developed to measure mechanical properties of fabrics under low loading. Fabric Assurance Testing System (FAST), developed by Commonwealth Scientific and Industrial Research Organization (CSIRO) in Austria, is widely used to measure fabric mechanical properties.

J.L. Hu, one of the most important researches in the field of fabric drape, explains drape as the hanging manner and shape of the fabric on a model form. This form might be a body or any surface where the fabric is supported from a part directly and the rest of the fabric is allowed to hang freely [5]. Moreover, evaluating fabric drape is another issue. Researchers have developed objective and subjective drape analysis methods during last decades [5]. Subjective drape analysis cause high level of errors. Thus some measurable and quantitative drape parameters are suggested. Drapemeter is the mostly used method to objectively measure drape parameters of a fabric. Cusick and Chu are the pioneers of the drapemeter. They developed a dimensionless value called "drape coefficient" (DC) to quantify the drapeability of the fabric which can be defined as the percentage of the area of the annular ring of fabric covered by a vertical projection of the draped fabric [6]. However drape coefficient is not alone enough to describe drapeability of the fabric. Because of that two very different fabrics may have same DC values, it is advised to consider drape appearance. Along with DC; node numbers, node locations, maximum and minimum amplitude of nodes, angle between two neighboring peaks of the folds help to understand drape profile of the fabrics [7]. Some drape parameters and their calculations are given in Fig.1. [8]
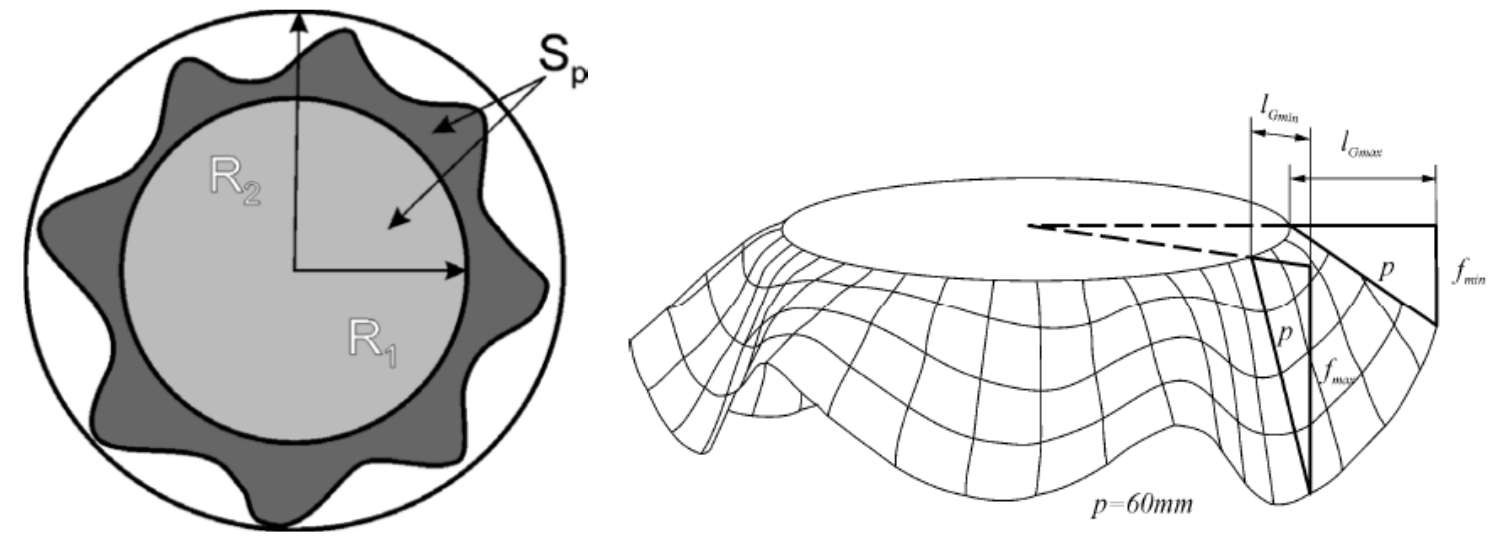

Fig.1. a) Projection of drape b) Maximum and Minimum Amplitudes

$D C=\frac{S_{p}-\pi R_{1}^{2}}{\pi R_{2}^{2}-\pi R_{1}^{2}} \times 100(\%)$

$S p$ : Area of the draped sample

$R_{1}$ : Radius of sample holder

$R_{2}$ : Radius of the non-deformed sample

$$
\bar{l}_{G}=\frac{\sum l_{G}(\mathrm{i})}{n}
$$

$l_{\text {Gmax }}$ : Maximum amplitude

$l_{\text {Gmin }}$ : Minimum amplitude

$\bar{l}_{G}: \quad$ Average amplitude

$n$ : $\quad$ Number of folds

Each fabric has a unique hanging manner. Fiber content, type of yarns, fabric structure and fabric finishing treatment influence fabric's drape behavior dramatically [3]. We know that fabric's mechanical properties and drape behaviors are strongly correlated with fabric types. Zhang at. al. tested some cotton, wool, silk and man-made fabrics and concluded that different compositions influence bending, creasing and draping properties of fabrics [9]. Jing and his colleagues' studies proved that yarn structure (yarn twist and yarn count) and weave of the fabric has a great influence on fabric's rigidity [10]. Moreover, another study concludes that fabric's thread density, yarn type and yarn count have significant effect on fabric's bending stiffness [11].

Many researcher tried to predict fabric drape behavior according to its mechanical properties and most of these researches confirm that fabric bending rigidity and shear rigidity has the highest correlation with fabric's DC [12] [13]. 
As mentioned recently virtual representations of fabrics become more of an issue, thus many researches concentrate on virtual drape analysis of fabrics. Plumlee et. al. wrote an article about the evaluation of 3D drape simulations of six different fabrics. They compared the drape behavior of fabrics in real and virtual environment. 3D scanners are used to capture the drape images of physical samples and virtual fabric drape is generated by a simulation software. They measured and compared node numbers, node heights, node width and drape coefficients of real and virtual fabrics [14]. Ngoc and Anh used six different fabrics and observed the drape behavior of the real garment and virtual garment. They used a commercial 3D simulation software ( $V$-stitcher) and observed drape coefficient and drape profile. They concluded that simulations reveal bigger and deeper fold waves while the real garment folds seems softer and smoother [15].

There are currently some available softwares to generate fabric and garment simulations. By using these softwares, 2D designs and patterns can be transformed to a 3D state. Some of these softwares allow users to insert fabric mechanical properties, thus enables users to obtain more realistic fabric drapes instead of a generic fabric appearance. The virtual fabrics are draped over virtual models by these softwares. 3D scanners are the appropriate instruments to generate the most accurate model image. Surface is scanned by a 3D scanner and scanned image is transmitted to the simulation software. Moreover, some softwares allow users to create their own parametric models by inserting some critical measurements to the software. Even though there are commercially available softwares offered for virtual fabric and garment display, discussions with clothing and pattern designers reveal that these softwares are not yet sufficient [14].

In this study three similar fabrics were chosen. Their blend ratios were identically same and these samples had the same weave construction (plain weave). Main difference between these three fabrics were their yarn counts and consequently their thread densities and weights.

The research approach might be separated into four parts as illustrated in Fig.2. Firstly, mechanical properties of fabrics were measured with FAST. Secondly, drape parameters of the fabrics were calculated with Cusick Drapemeter and drape profiles are captured by a digital camera. Thirdly, OptiTex simulation software is used to generate virtual drape of fabrics on a circular disk. Finally mechanical properties of the fabrics, real drape images of physical fabrics and virtual fabrics are compared.

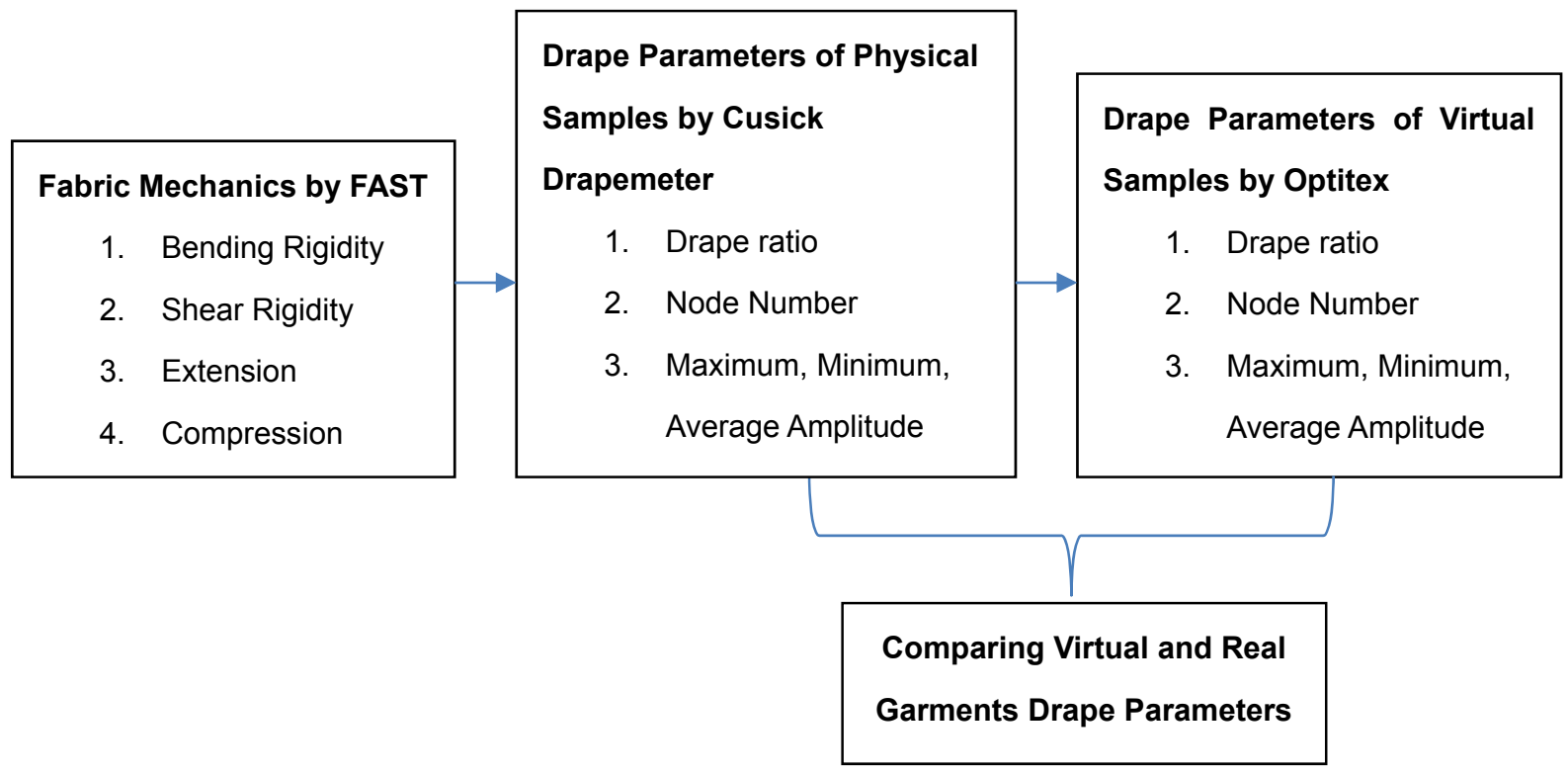

Fig. 2. Research Approach

\section{Experiments}

Three blend fabrics were supplied from a fabric company. Composition of the fabrics, weave construction and finish treatments are identically same (53\% polyester/ $43 \%$ wool, $4 \%$ elastane). Only yarn count of the fabrics, consequently thread density and weight of the fabrics are different. Textile properties of the test fabrics are listed in Table 1. 
Table 1. Textile Properties of the Test Fabrics

\begin{tabular}{|c|c|c|c|}
\hline & Weight $\left(\mathrm{g} / \mathrm{m}^{2}\right)$ & Yarn Count $\left(\mathrm{N}_{\mathrm{m}}\right)$ & $\begin{array}{c}\text { Thread Density }(\text { Warp/ } \\
\left.\text { Weft numbers per } \mathrm{cm}^{2}\right)\end{array}$ \\
\hline FABRIC A & 162 & $80 / 2$ & 25 ends $/ 25$ picks \\
\hline FABRIC B & 185 & $56 / 2$ & 24 ends $/ 24$ picks \\
\hline FABRIC C & 147 & $100 / 2$ & 30 ends/30 picks \\
\hline
\end{tabular}

As mentioned recently, in the first stage of the research fabrics are tested with FAST system. Prior to measurements, fabrics are conditioned in climate chamber for 24 hours $\left(20 \pm 2{ }^{\circ} \mathrm{C}, 65 \pm 2 \%\right.$ humidity). FAST 1 (compression meter), FAST 2(bending meter), FAST 3 (extension meter) tests are applied according to literature [16].

Second stage is accomplished by measuring the drape properties of physical samples by Cusick Drapemeter. Cusick drapemeter consists a horizontal disk with $18 \mathrm{~cm}$ diameter. Each fabric sample is cut to $30 \mathrm{~cm}$ diameter and these pieces are centered on the disk. Fabrics are allowed to hang freely on the disk to observe their drape behaviors. The measurements were repeated 10 times for each fabric sample and average drape parameters were calculated. A digital camera is placed on the top of the disk to transmit draped fabric images to the computer and an image analysis software calculated the node numbers, drape ratios and maximum, minimum and average amplitude values of the samples. For drape analysis it is also important to consider drape appearance and face of the fabric. In this study only the front face of the fabric is analyzed.

Observing virtual drape properties of the fabrics constitute the third stage. The purpose is to compare real and virtual drape properties. Thus initially we prepared a virtual disk with $18 \mathrm{~cm}$ diameter in "3ds Max" program which represents the real disk in Cusick Drapemeter. This image is exported into OptiTex software which is widely used for 3D simulations. Fabric patterns with $30 \mathrm{~cm}$ diameter are also prepared by OptiTex pattern design system (PDS). Simulation tool of the OptiTex program requires mechanical properties of the fabrics. Fabric properties obtained by FAST is inserted to the OptiTex system (units of FAST and OptiTex are different thus a conversion of units are primarily done). There are several restrictions in OptiTex program. The program allows minimum fabric thickness as $0.5 \mathrm{~mm}$, however our three fabrics were below $0.5 \mathrm{~mm}$. Consequently we had to enter thickness value as 0.5 $\mathrm{mm}$ for each fabric. Moreover friction values are also required in OptiTex for simulations. Unfortunatly friction values are not measured in FAST system. Thus friction parameter were chosen by help of an expert of OptiTex software Finally friction is fixed at 0.8 for each fabric.. Images are simulated in OptiTex program and saved as jpeg files. These images are then analyzed in "ImageJ" free software where distances and areas can be calculated from the drape images [17]. Accordingly, drape parameters of virtual samples are calculated by the help of ImageJ software.

\section{Results and Discussion}

The research is separated into four stages thus the results are given in four different headings.

\subsection{Fabric Mechanical Properties}

As explained in experiments part, mechanical properties are measured by FAST system and results of measurements are given in Table 2.

Table 2. FAST Results of the Test Fabrics

\begin{tabular}{|c|c|c|c|c|c|c|c|c|c|}
\hline & \multirow[t]{2}{*}{$\begin{array}{c}\text { Fabric } \\
\text { Thickness } \\
(\mathrm{mm})\end{array}$} & \multicolumn{2}{|c|}{$\begin{array}{l}\text { Bending } \\
\text { Rigidity } \\
(\mu \mathrm{N} \cdot \mathrm{m})\end{array}$} & \multirow[t]{2}{*}{$\begin{array}{l}\text { Shear } \\
\text { Rigidity } \\
(\mathrm{N} / \mathrm{m})\end{array}$} & \multirow[t]{2}{*}{$\begin{array}{c}\text { Compression } \\
\text { (mm) } \\
\text { (Under } 100 \\
\text { g/cm load) }\end{array}$} & \multicolumn{2}{|c|}{$\begin{array}{c}\text { Extension } \\
(\%) \\
\text { (Under (Under } \\
100 \mathrm{~g} / \mathrm{cm}^{2} \text { load) }\end{array}$} & \multicolumn{2}{|c|}{$\begin{array}{l}\text { Formability } \\
\left(\mathrm{mm}^{2}\right)\end{array}$} \\
\hline & & Warp & Weft & & & Warp & Weft & Warp & Weft \\
\hline FABRIC A & 0.39 & 3.3 & 2.7 & 30 & 0.328 & 6.8 & 9.9 & 0.4 & 0.46 \\
\hline FABRIC B & 0.427 & 4.5 & 4.1 & 43 & 0.366 & 4.1 & 6.7 & 0.28 & 0.43 \\
\hline FABRIC C & 0.352 & 3.3 & 3.5 & 33 & 0.29 & 5.1 & 5.8 & 0.28 & 0.32 \\
\hline
\end{tabular}




\subsection{Drape Parameters of Physical Samples}

Drape behavior is observed by Cusick drapemeter and images are captured by a digital camera. Fig. 3 . shows the drape images of three different samples. Drape parameters are important to understand fabric behavior. However completely different fabrics may have same drape parameters, so comparing drape parameters are not alone enough. Therefore drape images should be also analyzed.

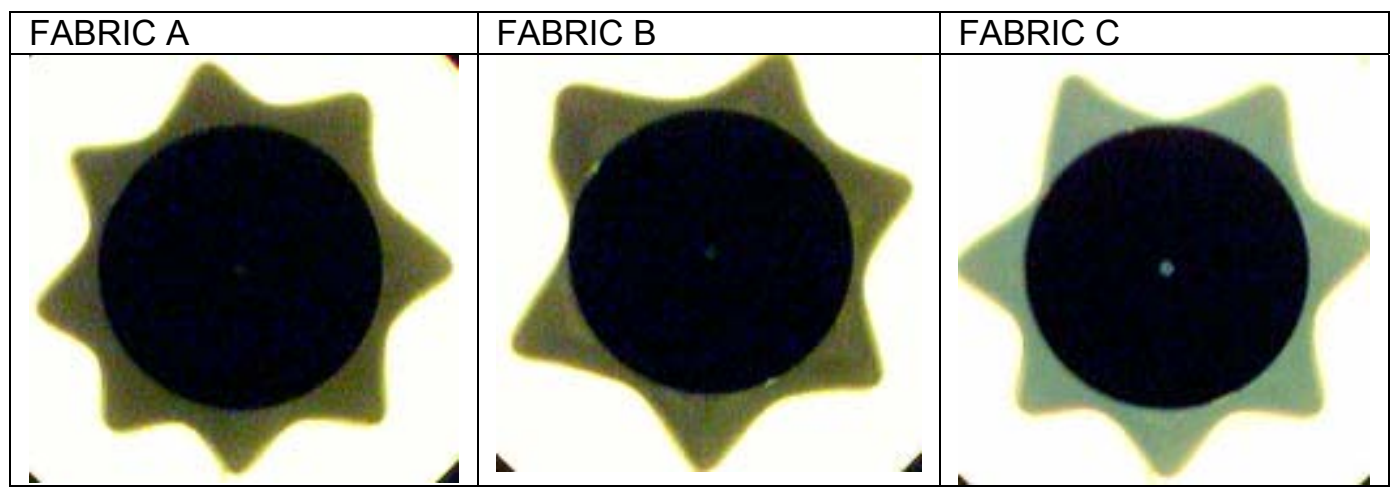

Fig. 3. Drape images of physical samples (tested by Cusick Drapemeter)

An image analysis software calculates the drape parameter according to Fig.3. and calculated drape parameters of the physical samples are shown in Table 3.

Table 3. Drape Properties of Physical Samples According to Cusick Drapemeter Tests

\begin{tabular}{|l|c|c|c|c|c|}
\hline & Drape Ratio & $\begin{array}{c}\text { Number of } \\
\text { Nodes }\end{array}$ & $\begin{array}{c}\text { Minimum } \\
\text { Amplitude } \\
(\mathrm{cm})\end{array}$ & $\begin{array}{c}\text { Maximum } \\
\text { Amplitude } \\
(\mathrm{cm})\end{array}$ & $\begin{array}{c}\text { Average } \\
\text { Amplitude } \\
(\mathrm{cm})\end{array}$ \\
\hline FABRIC A & 0.33 & 7.6 & 9.44 & 13.58 & 11.29 \\
\hline FABRIC B & 0.34 & 6.4 & 9.17 & 13.86 & 11.32 \\
\hline FABRIC C & 0.33 & 7 & 9.4 & 13.48 & 11.28 \\
\hline
\end{tabular}

\subsection{Drape Parameters of Virtual Samples}

Fig. 4. shows the drape images of fabrics from top that are generated by OptiTex program. Measured mechanical properties of fabrics are used to generate these images.

\begin{tabular}{|c|c|c|}
\hline FABRIC A & FABRIC B & FABRIC C \\
\hline
\end{tabular}

Fig. 4. Drape simulations of fabric samples in OptiTex

Final calculations were done to obtain drape parameters of virtual samples. Images in Fig. 4. were analyzed in ImageJ software and calculated drape parameters of virtual samples are given in Table 4. 
Table 4. Drape Properties of Virtual Samples According to Image Analysis

\begin{tabular}{|l|c|c|c|c|c|}
\hline & Drape Ratio & $\begin{array}{c}\text { Number of } \\
\text { Nodes }\end{array}$ & $\begin{array}{c}\text { Minimum } \\
\text { Amplitude } \\
(\mathrm{cm})\end{array}$ & $\begin{array}{c}\text { Maximum } \\
\text { Amplitude } \\
(\mathrm{cm})\end{array}$ & $\begin{array}{c}\text { Average } \\
\text { Amplitude } \\
(\mathrm{cm})\end{array}$ \\
\hline FABRIC A & 0.31 & 8 & 9.23 & 13.47 & 11.32 \\
\hline FABRIC B & 0.38 & 8 & 9.49 & 13.47 & 11.84 \\
\hline FABRIC C & 0.39 & 8 & 9.83 & 13.82 & 11.81 \\
\hline
\end{tabular}

\subsection{Comparison of Real and Virtual Drape and Mechanical Properties}

Talking about the real fabrics; Fabric $B$ gives the lowest node number. This might be due the fact that Fabric $B$ has the thickest yarns, therefore has the highest fabric weight and its measured bending and shear stiffness is the highest among other two fabrics. Opposite way round, Fabric A has the highest node number while it has the lowest bending and shear stiffness values. As explained in introduction part, bending and shear properties of the fabrics have the highest correlation with fabrics' drape properties. This study also confirms this assumption. However the main purpose of this study is to compare virtual and real drape parameters. The drape appearance of virtual and real fabric samples are slightly different. Real fabric folds are sharper than virtual folds. Moreover when we compare drape appearances it is clear that fold distribution of real fabrics are more even than virtual folds. No significant different is noticed between the virtual and real fabrics' fold amplitudes. The main difference between real and virtual drape can be observed as node numbers. Virtual garments have 8 nodes, however the average fold numbers of real fabrics are lower than this value. Especially Fabric $B$, due to its stiffness, have a 6.4 average fold number. When the virtual and real drape images of Fabric $B$ is compared, it is clearly visible that the real fabric is a lot stiffer and drapes less when compared to its virtual counterpart. Drape ratios of virtual fabrics seem to be higher than their physical counterparts. Drape ratio is positively correlated with stiffness of the fabrics. The higher drape ratios of virtual fabrics should point stiffer drape behavior. However for stiffer fabrics we also expect less folds. In contrary, fold numbers of virtual fabrics are higher in contrast with their stiffness which should be investigated. While considering virtual drape images and parameters, the issue about thickness and friction of fabrics should be kept in mind. As mentioned earlier, OptiTex program does not allow to enter any thickness value lower than $0.5 \mathrm{~mm}$, however the tested fabrics have lower thickness values then 0.5 $\mathrm{mm}$, eventually we had to insert the lowest value that program allows, $0.5 \mathrm{~mm}$ in this case, for each fabric. Additionally FAST system do not measure friction values of the fabrics. Therefore with the help of an expert we concluded that friction value 0.8 gives the best simulation results for test fabrics. Consequently, friction is fixed at 0.8 for each fabric.

\section{Conclusion}

The mechanical properties of three similar fabrics (same composition, same weave, different yarn count) are measured by FAST system. Even though fabrics are similar there are slightly differences between their bending and shear rigidities. The real drape properties of fabrics are different then each other. Fabric with highest bending and shear rigidity (Fabric B) has the lowest node number average. However other drape parameters (drape ratio, amplitudes) do not show any significant difference for each fabric. The main purpose of the study was to compare real and virtual drape of fabrics. The virtual drape images of fabrics are quite different than their real counterparts. The most significant difference is their node numbers. The virtual fabrics have higher node numbers and the node shapes are quite different. Real fabric folds have sharper edges then virtual folds. Even though the drape images are different then each other, drape parameters of virtual and real fabrics are very close to each other. Especially maximum, minimum and average amplitudes are almost same. However drape ratio of virtual fabrics are higher than the real fabrics for Fabric B and Fabric $\mathrm{C}$. According to literature higher drape ratios are positively correlated with stiffness of the fabrics. Stiffer fabrics are expected to have lower node numbers. But we see that virtual fabrics have higher node numbers opposite way round. It should be also considered that there are some restrictions for the study. The OptiTex program do not allow to insert any fabric thickness value which is lower than $0.5 \mathrm{~mm}$. However many fabrics, such as voile and chiffon, are a lot thinner than $0.5 \mathrm{~mm}$. 
FAST measurements are fast and cheap to test mechanical properties of fabrics but the friction is not measured in FAST system. Thus for further researches it may be better to use Kawabata Evaluation System (KES) where 16 different fabric properties are measured. In this research we only evaluated the face of the fabric. In the future back of the fabric may be also evaluated to investigate if faces of the fabric has an influence on drape behavior. In this research the real fabric sample drape images are captured by a digital camera. However 3D body scanners are also an option to scan fabric samples. By doing so, image analyzes can be done more accurate. 3D scanners may allow researchers to see the drape behavior from all sides of the fabric while captured camera image allows to view the fabric only from the bottom view.

\section{Acknowledgment}

We thank to Sansal Cetin and Bahariye Tekstil who helped us to provide sample fabrics. We also appreciate Unzile Hacioglu and Mektas Makina for providing us OptiTex program and for presenting their expertise.

\section{References}

[1] G. K. Stylios and T. R. Wan, "The Concept of Virtual Measurement 3D Fabric Drapeability," International Journal of Clothing Science and Technology, vol. 11, no. 1, pp. 10-18, 1999.

[2] "Retailing: Euromonitor from trade sources/national statistics," Euromonitor International, 2013.

[3] N. Kenkare , T. A. M. Lamar, P. Pandurangan and J. Eischen, "Enhancing Accuracy of Drape Simulation. Part I: Investigation of Drape Variability via 3D Scanning," The Journal of The Textile Institute, vol. 99, no. 3, pp. 211-218, 2006.

[4] F. T. Pierce, "The Handle of Cloth as a Measurable Quantity," J. Text. Inst., vol. 21, no. 9, pp. 377-417, 1930.

[5] J. L. Hu, "A Review on the Study of Fabric Drape," Journal of Hong Kong Institution of Textiles \& Apparel, pp. 126-136, 1997.

[6] C. C. Chu, C. L. Cummings and N. A. Teixeira, "Mechanics of Elastic Performance of Textile Materials, Part V: A study of the factors affecting the drape of fabrics- The development of a drape meter," Textile Research Journal, vol. 20, pp. 539-548, 1950.

[7] S. Jevsnik and D. Zunic-Lojen, "Drape Behavior of Seamed Fabrics," Fibers and Polymers, vol. 8, no. 5, pp. 550-557, 2007.

[8] S. Jevsnik and J. Gershak, "Modelling the Fused Panel for a Numerical Simulation of Drape," FIBRES \& TEXTILES in Eastern Europe, vol. 12, no. 1(45), pp. 47-52, 2004.

[9] H. Zhang, H. Zhu and J. Zhang, "Properties of Fabric Between Bending,Creasing and Draping," Wool Textile Journal, no. 3, pp. 58-61, 2003.

[10] W. Jiang, "Relationship Between the Structure and Rigidity and Elasticity of Light-weight Worsted Fabrics," Wol Textile Journal, no. 3, pp. 49-52, 2010.

[11] M. Nofitoska, G. Demboski and M. F. Ângelo , "The Effect of Fabric Structure Variation on Garment Aesthetic Properties," Tekstil ve Konfeksiyon, no. 2, pp. 132-136, 2012.

[12] B. J. Collier, "Measurement of Fabric Drape and its Relations to Fabric Mechanical Properties and Subjective Evaluation," Clothing and Textiles Research Journal, vol. 10, no. 1, pp. 46-52, 1991.

[13] J. Hu and Y. F. Chan, "Effect of Fabric Mechanical Properties on Drape," Textile Research Journal, vol. 68, no. 1, pp. 57-64, 1998.

[14] T. May-Plumlee, J. Eischen, N. Kenkare and P. Pandurangan, "Evaluating 3D Drape Simulations: Methods and Metrics," National Textile Center Annual Report, North Carolina , 2002.

[15] N. T. Ngoc and H. N. Anh, "Investigating on Fabric and Skirt Drape in Clothing Construction," in Seventh International Conference- TEXSCI 2010, Liberec, 2010.

[16] A. De Boos and D. Tester, "SiroFAST: Fabric Assurance by Simple Testing," in Effect of Physical and Mechanical Properties on Fabric Hand, Cambridge, Woodhead Publishing , 2005, pp. 433-461.

[17] W. S. Rasband, "Image Processing and Analysis in Java (ImageJ)," U. S. National Institutes of Health, Bethesda, Maryland, USA, 1997-2014. [Online]. Available: http://imagej.nih.gov/ij/. [Accessed 24 August 2015]. 